Portland State University

PDXScholar

\title{
Making Makeup: a Recipe Book for All-Natural Cosmetics
}

Jessica Arlich

Portland State University

Follow this and additional works at: https://pdxscholar.library.pdx.edu/honorstheses

\section{Let us know how access to this document benefits you.}

\section{Recommended Citation}

Arlich, Jessica, "Making Makeup: a Recipe Book for All-Natural Cosmetics" (2017). University Honors Theses. Paper 433.

https://doi.org/10.15760/honors.429

This Thesis is brought to you for free and open access. It has been accepted for inclusion in University Honors Theses by an authorized administrator of PDXScholar. Please contact us if we can make this document more accessible: pdxscholar@pdx.edu. 
Making Makeup: A Recipe Book for All-Natural Cosmetics

by

Jessica Arlich

An undergraduate honors thesis submitted in partial fulfillment of the requirements for the degree of

Bachelor of Arts/Science

in

University Honors

and

Graphic Designer

Thesis Adviser

Elisabeth Charman

Portland State University

2017 
making makeups 
Are you a makeup enthusiast? Do you ever find yourself concerned that

ou can't pronounce anything in the ingredient list? If you're like millions

of Americans, you're increasingly aware of what you're putting on and in

Making Makeup

Inside, you will find a ton of great information on how to create your own

cosmetics, fun recipes, and good resources to turn to.

Have fun!

Jessica

\section{By Jessica Arlich}


Copyright $\odot 2017$ by Jessica Arlich

All rights reserved. This book or any portion thereo

may not be reproduced or used any mannerwhatsoever

without the express written permission of the publisher

except for the use of brief quotations in a book review.

Printed in the United States of America

First Printing, 2017

ISBN 0-9000000-0-O

Little Bird Publishing

1234 Couch Street
Portland, oR 97035

www.littlebirdbooks.com 


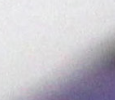

contents

Introduction

Things You Will Need
Equipment
Ingredients

Eye Makeup 


\section{玫 . \\ about this book}

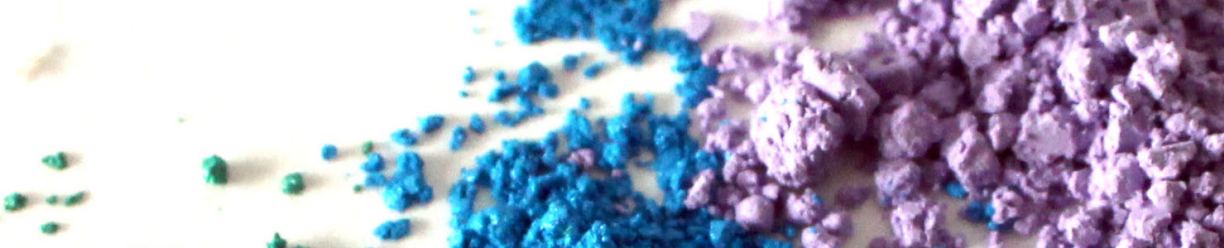
wo s.

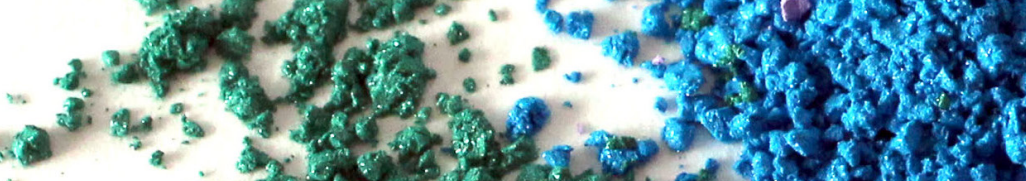

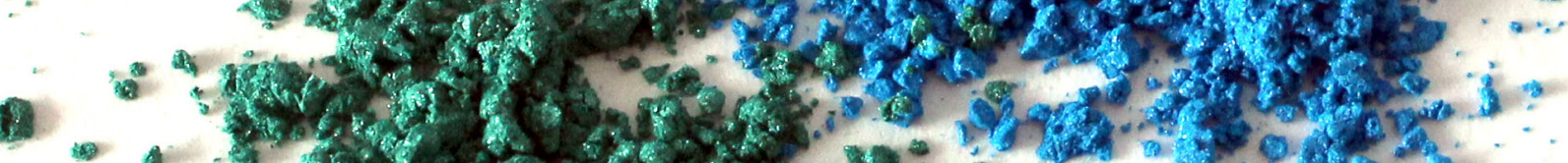

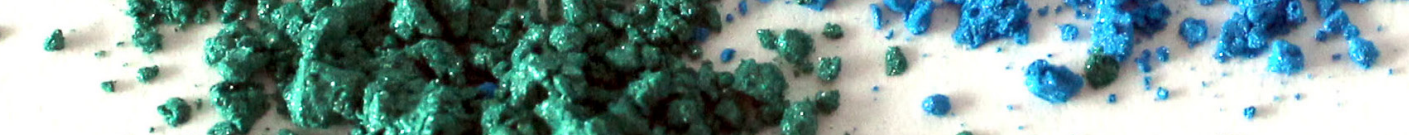

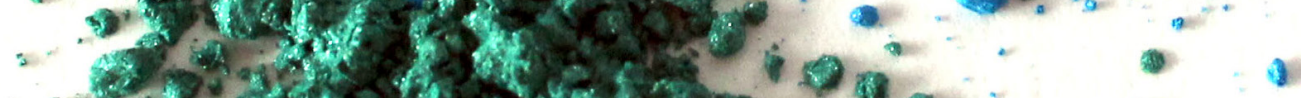

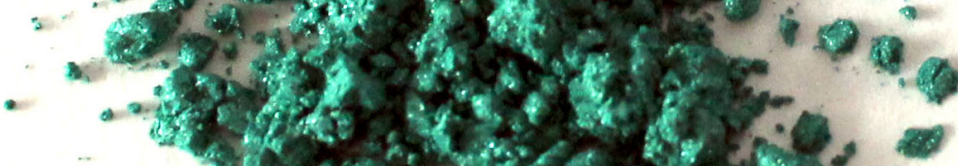

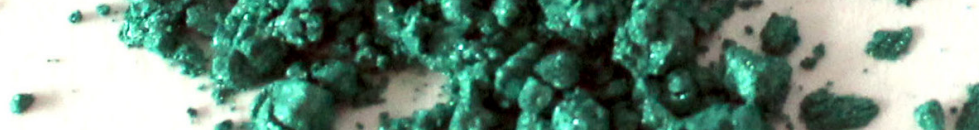

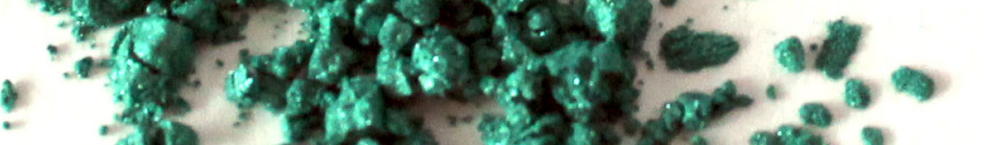

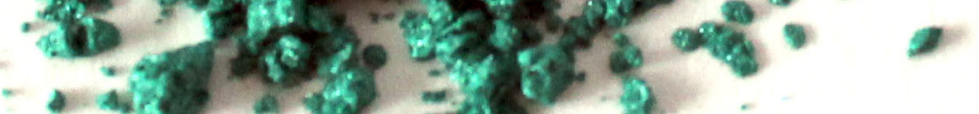

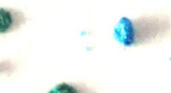

.

There is a revolution happening in our midst. There has been increasing demand for organic and all-natural consumables in the United States ev ery year. We not only see this in counterculture anymore. More and more mainstream culture is questioning the safety of the things they use, people shopping at places like Whole Foods or local markets. The usda reports that between 2014 and 2015, "the number of domestic certified organic operations increased by almost 12 percent." That's "an increase of nearly 300 percent since the count began in 2002." Clearly, people are becoming concerned about what they're putting into their body.

The easiest way to ensure you know what how safe your products are besides lots of careful research, is to prepare things for yourself. This makes it poss for like-mind indiriduas to share what they've learned so that everyone can benefit and make safe products.

YouTube hosts a multitude of popular channels where "beauty gurus" post vlogs about skincare routines, product reviews, creating certain looks, techniques, and how to apply cosmetics for your face shape. Other social media outlets, such as Instagram or Snapchat have more compressed versions of any of these. Places like Pinterest and natural-wellhess blogs provide free resources to creating your own makeup, with lots of pictures and tep bystep instructions.

Making your own products is not only safer, but it can be a lot of fun tool

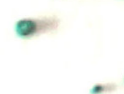


what you will need 
equipencent \& containcers

Mortar and Pestle/Coffee grinder/Food Processor While you can certainly go the old-fashioned route and use a mortar and pestle to grind your ingredients,
it's much quicker and easier to use a coffee grinder or food processor. You get a more even grind as well.

Grater
You might need this to break ingredients into smaller pieces so that they melt quicker.

Double Boiler Saucepans

In the event that you use a stovetop to create your product, a double boiler is often helpful in order to

Cooking Utensils

These are helpful for stirring and mixing

Measuring Spoons

A multitude of small spoons will help maintain an accurate ratio of ingredients.

Stove or Microwave

This will be used to melt your ingredients

Glass measuring cup

This helps not only in measuring out ingredients,

but can also be used as a vessel to heat ingredients

in a microwave.
Bowls

measuring or measuring ingredients, it's ood to have lots of bowls to hold them in.

Containers

When finished, products will need to be housed in

Funnels
These are helpful for getting warm, liquid product into their containers.

Latex Gloves/Face Mask

When working with ingredients, especially over heat, it's a good idea to use protection.

Tamper will flatten and set products flat. You can cheat and skip the expensive tools by using wooden dowels.

Eyedropper

Droppers will help when using very small amounts of liquids, like essential oils. some sort of container.

A tamper with a diameter equal to your container's
Glass/Plastic/Metal Tubs

These are good for holding things like balms, fountions, and eyeshadows. Of these three materials,

Lipstick Tubes

These can be easily purchased online in bulk and come in different colors and materials.

Mascara Wand Tube

Wands come in a variety of shapes and sizes. Some prefer a thick wand while others like sparse and curved wands.

Hollow Pencils

These can be filled with eyeliner, brow filler, or even

lip liner!

Vials with Brushes

Vials with brush caps can be used for things like

liquid eyeliner or lip gloss. 


\section{ingredients}

Be aware of the ingredients you use! Many of these are derived from nuts and may
cause a reaction to those with an allersy

Butters

Butters are less hard than waxes. They come from plants and provide different advantages.

Shea Butter

Cocoa Butter

fragrant and stable, also popular

Kokum Butter

won't clog pores

Mango Butter

harder, but moisturizes
Waxes

re what provide stability and thickness to your products. They help hold everything togethe Waxes are usually pretty hard and will need to be melted down for use. For quicker melting it's best to buy waxes in pastilles, or pellets. Of these waxes beeswax is the easiest to work with. You may have to use significantly less of the other waxes due to how hard they are.

Beeswax

esiliant, available and inexpensive

Canelilla Wax

vegan, higher melting point

Carnauba Wax

vegan, hardest wax

Emulsifying Wax

vegan 
Remember: less is more. Try to limit the

amount of ingredients that you use.

Clays

These are most used in foundations. Some are better

for oily skin and some are better for dry skin. Make

you don't unncessarily dry out your skin!

Bentonite Clay

Ight-grey, exfoliates and dries

French Green Clay

Kaolin Clay

white or colors, nourishes

Morrocan Red Clay

cleans and dries

Morrocan Rhassoul Clay

nourishes, tones
24

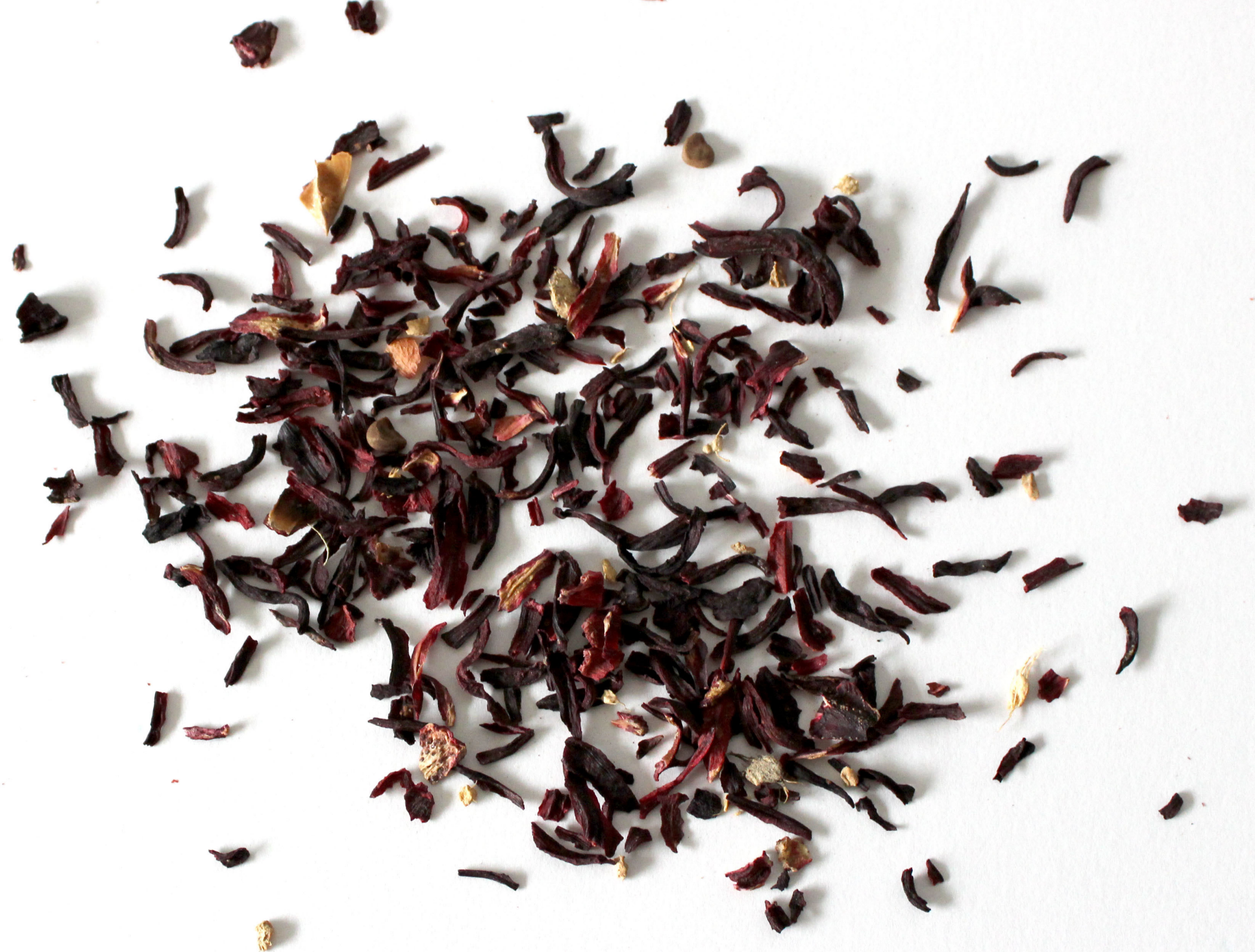


Carrier Oils

Also known as base oils, these oils are derived from the fat in plants. They are used to dilute essential oils and carry the scent in to the skin to be absorbed. In general, they do not have a strong scent of their own. locking in moisture and lubrication.
LIGHT

Conut Oil

good for scent, moisturizes

Grapeseed Oil heals, won't clog pores
MEDIUM

softens and hydrat

Sweet Almond Oil softens and protects

Apricot Kernel Oil for sensitive skin, protects
HEAVY

Avocado Oil

moisturizes and protects

Castor Oil

used for glos

Vegetable Glycerin

This syrup is derived from plant oils. It helps the 


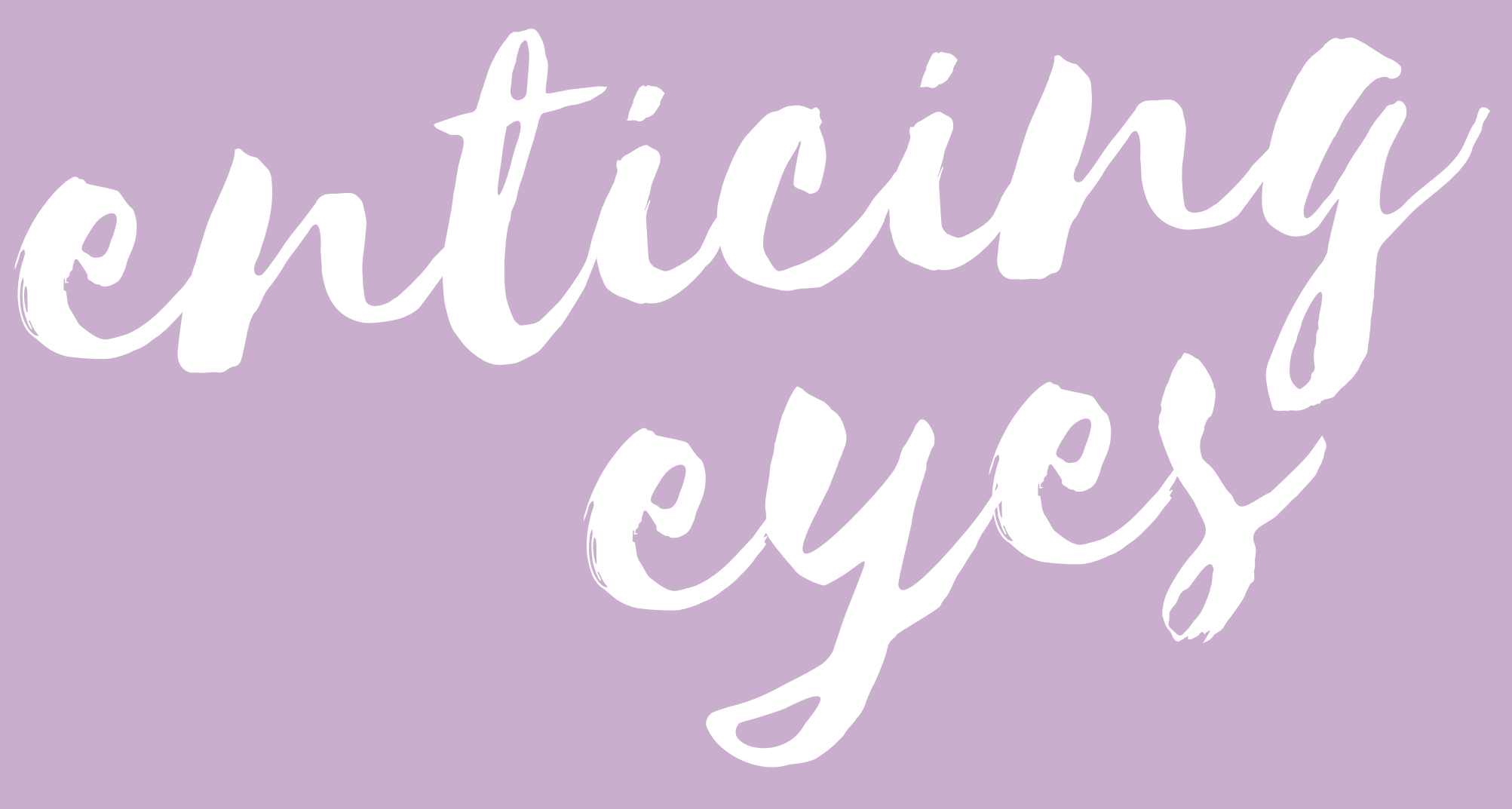

When it comes to making eyeshadows, the possibilites are limited only by your own imagination. There are a huge range of micas available for With liners and mascaras, make sure to work quickly to get your product into containers before it starts to solidify!

Since these products are going near your eyes, make sure you're careful about what you're putting in them. 


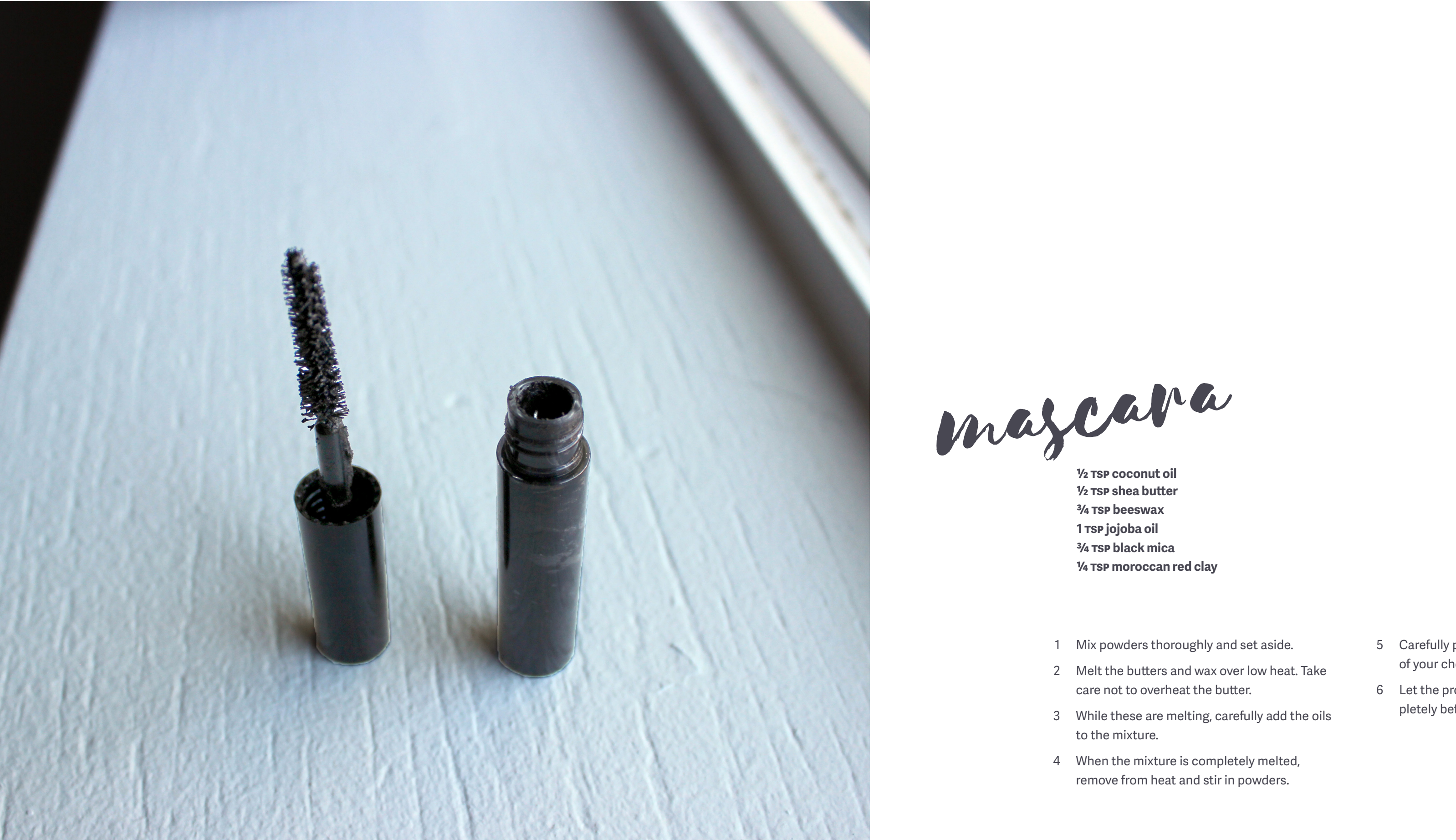


eycliner 
cye shadow 


$$
\text { For lip stick, instead use 1 part oil. }
$$

1 Melt the butters and wax over low heat. Take care not to overheat the butter.

While these are melting carefully add the ols to the mixture.

then mix

remove from heat and stir.

4 Quickly add the essential oils and stir until everything has mixed together completely.

5 Carefully pour your product into

Let the product cool uncovered and completely before use. shiny, while clay will make it matte. 


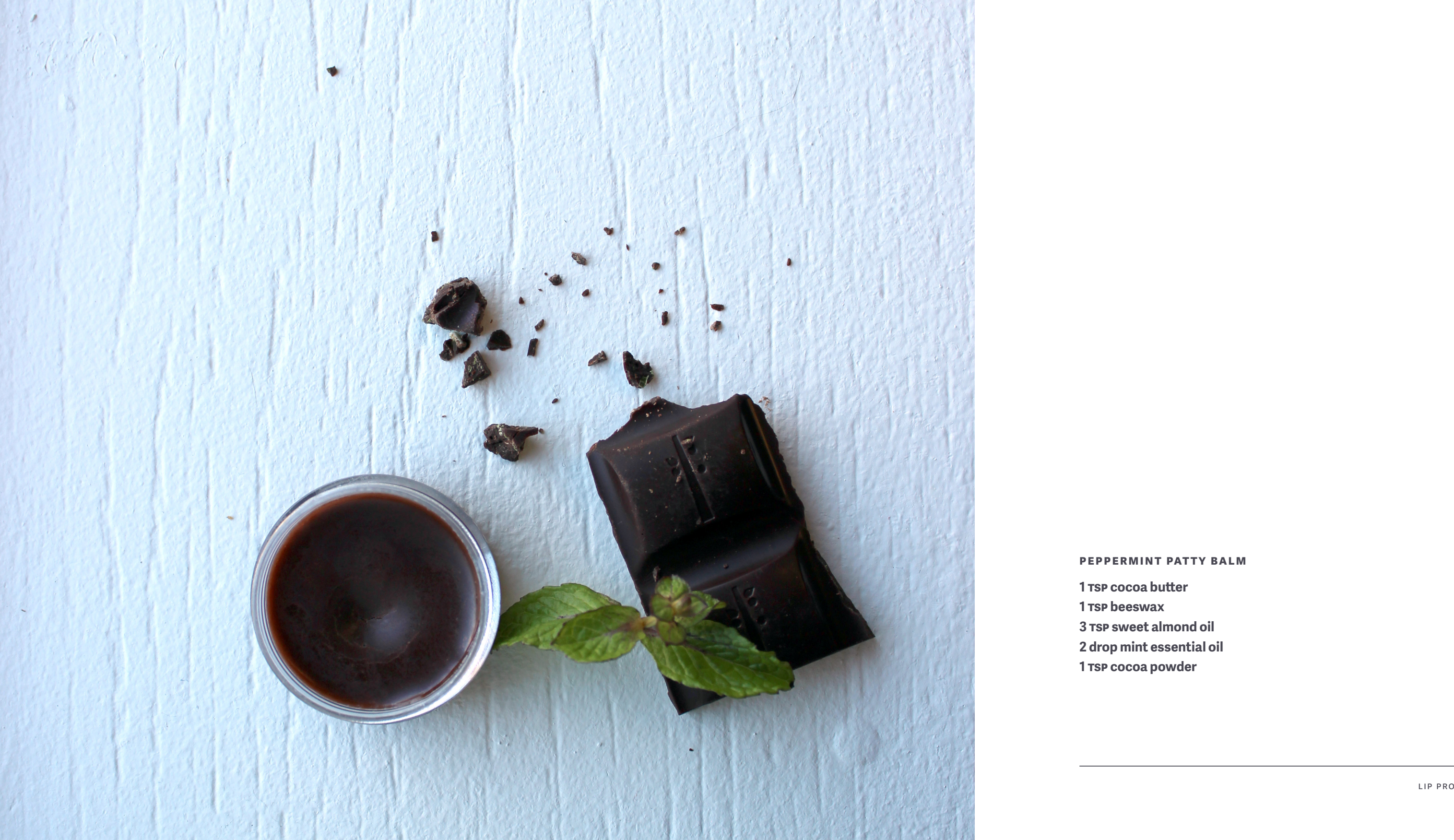




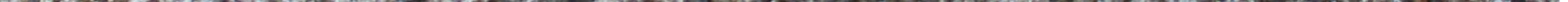


face powders 
color correcting

toner guide

Color correction can take your makeup look to a whole new level. Using
simple color theory you can easily hide blemishes and dark spots to draw more attention to the areas you want to show off!

You can make a color corrector by adding different colored micks or
ground herbs to your product.

Use on deep skin tones.

peach

Corrects green undertones.

Use on fair and medium skin tones.

Use under eyes. Corrects blue undertones and brightens.
Use pumpkin, clays, or mica.

Use on deep skin tones with warm tones.
Use under eyes. Corrects dark spots.

Use turmeric, clays, or mica.

yellow

green

blue

purple

white
Use on all skin, especially olive or tan skin. Good for aging skin.

Corrects purple and red undertones.

Use on all skin tones, especially acne-prone.

Corrects red undertones.

Use on fair skin with cool tones.

Corrects yellow undertones and hyperpigmentation.

Use on medium skin with cool tones, especially dull skin.
Corrects yellow undertones.

Corrects yellow undertones.

Use berries, alkanet, clays, or mica.

Use on all skin tones.

40 FACE MAKeup 

1 TSP cocoa powder

$1 / 2$ TSP cosmetic clay

$1 / 2$ TSP cosmetic clay

$1 / 2$ TSP ground ginger

$1 / 2$ TSP ground nutmeg

$1 / 4$ TSP arrowroot powder

$1 / 8$ TSP cinnamon essential oil

MAHOGANY SPICE BLUS

1 TBSP arrowroot powder

1 TSP morrocan red clay

1 Tsp cocoa powder

$1 / 4$ TSP beet root powder

$1 / 4$ TSP ground cinnamo

$1 / 8$ TSP ground clove
$1 / 8$ TSP frankincense essential oil

HAUTE PINK BLUSH

1 TBSP arrowroot powder

1 TSP cosmetic clay

$y_{4}$ TSP ground dried strawberries

$1 / 8$ TSP jasmine essential oi

\section{WINE BLUSH}

1 TBSP arrowroot powder

1 TSP morrocan red clay

1 TSP cocoa powder

$y_{2}$ TSP ground alkander

$1 / 3$ Tsp ground clove

$y_{8} / y_{8}$ TSP ground clove essential

$1 / 8$ TSP rose essential oil

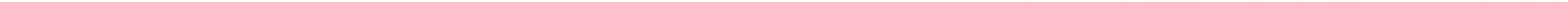


(Pictured) FOUNDATION FOR DEEP SKIN

1 TBSP moroccan red clay

2 TSP cocoa powder

TSP arrowroot powde

$1 / 4$ TSP ground ginger
$1 / 8$ Tsp jojoba oil

FOUNDATION FOR FAIR SKIN

1 TBSP arrowroot powder

2 TSP cocoa powder

1 TSP cosmetic clay

$1 / 4$ TSP ground cinnamo

$1 / 8$ sSp ground spirulina
$1 / 8$ TSP rose essential oil 
SPECIAL THANKS TO

Lis Charman

Dr.Stephanie Skourtes

\section{ABOUt THE AUTHOR}

Jessica Arlich is a designer living in the Portland

metropolitan area with her two cats. She's got quite the addiction to La Croix and chocolate. She places high value on her carefully-sculpted brows. 


\section{"Surprisingly simple and fun!" - PORTLAND MERCURY}

If you're like millions of Americans, you're growing increasingly aware of what you're putting into your body. What better way to know what ingredients are in your products than to make them yourself?

Creating your own cosmetics is actually really fun and easy!

LIttle Bird Publishing

Portland, on littlebirdbooks.com

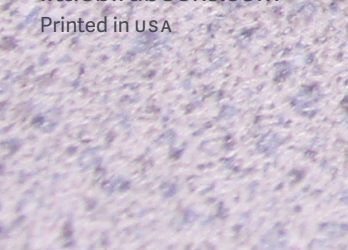

